\title{
LUIS CARLOS LOPEZ VISTO POR SU HERMANO
}

\author{
POR \\ STANKO B. VRANICH \\ Herbert H. Lehman College, CUNY
}

E1 año 1961, al emprender un trabajo en el seminario sobre poesía hispanoamericana, dirigido por don Arturo Torres Rioseco, en Berkeley, California, acerca del poeta colombiano Luis Carlos López, realicé investigaciones no solamente en las bibliotecas, sino poniéndome en contacto epistolar con varios compatriotas y un familiar del poeta. De la cordial respuesta que recibí de todos llevo el más grato recuerdo: don Aníbal Esquivia Vázquez, don Alberto Miramón, don Eduardo Caballero Calderón, don Carlos García Prada y don Domingo López Escauriaza, hermano del poeta, con quien intercambié varias cartas. Pedí a éste que apuntara algunos recuerdos, datos e impresiones de su hermano, y tan en serio tomó mi propuesta, que antes de un mes recibí una carta suya con nueve páginas adjuntas. Todo lo he guardado desde entonces en mi archivo, mientras que las andanzas de investigador me llevaban por otros caminos de las letras hispánicas.

Según he podido averiguar, siguen inéditas las noticias contenidas en aquellas cuartillas. Con ocasión del vigésimo aniversario de la muerte del poeta, don Domingo publicó una columna en el periódico que editaba, $E l$ Universal, de Cartagena, «Un recuerdo familiar sobre Luis Carlos López»; es lo único que se cita en recientes tesis sobre la vida y la obra del poeta.

La triste nueva de que la pluma de don Domingo no podrá añadir más datos sobre su hermano, ni él publicar íntegro lo que había redactado, me impulsaron a mandar carta y hojas a las prensas como cálido recuerdo de ambos y en beneficio de cuantos estudian las letras colombianas. (S. B. V.) 
Dos textos del hermano de Luis Carlos López

Señor D. Stanko B. Vranich

Cartagena, marzo 15 de 1963.

Calle Pimienta 12

Sevilla, España

Muy distinguido señor:

Recibí con algún retraso, por estar ausente de la ciudad, su apreciable e interesante carta de 27 de enero último. A mi regreso tuve el placer de enterarme de ella y de sus propósitos en relación con la obra literaria de mi hermano Luis Carlos.

Deseo presentarle mis excusas por no haber podido ser atento con usted en la primera ocasión en que me dirigió la otra carta que no llegó a mis manos ni tuve conocimiento de ella hasta que hablé con el estimable caballero señor don Ebel Botero, a quien expresé mi pena por lo sucedido y le pedí el favor de darle una explicación con mi deseo de que usted me hiciera el honor de escribirme de nuevo.

Hoy, satisfecha esta aspiración mía, y aclarado el penoso incidente, debo referirme a los términos elogiosos de su carta sobre Luis Carlos. Nada más honroso para su nombre y su obra que sea usted, un consagrado crítico y un ilustre literato, tan amable en sus apreciaciones sobre la labor que él cumplió en el campo de las letras. A sus familiares, especialmente, la noticia que usted me da sobre su deseo de hacer una edición crítica, con introducción biográfica, de la obra poética de mi hermano, nos llena de satisfacción y compromete nuestra gratitud para con usted.

Francamente le digo que nunca he escrito sobre la personalidad intelectual de Luis Carlos. Con él no sólo me ligaron los lazos de la sangre, sino una permanente y afectiva unión que se extendió a muy comunes aficiones de orden literario. Desde luego no vaya a suponer que ellas tuvieran algo que ver con la poesía. Pero la carrera del diarismo, que he seguido modestamente, tuvo su origen en una de las bromas a que era muy inclinado el temperamento de Luis Carlos. La cosa no vale pena de contarla. Si se lo menciono es para decirle que las líneas escritas por mí, muy a la ligera, sobre algunos recuerdos familiares de mi hermano, que le estoy enviando, están dictadas por esos sentimientos. No hay en ellas ningún juicio literario, campo para mí vedado. Además, he querido complacerle estimulado por su obligante y gentil solicitud.

Recuerdo mucho al eminente catedrático doctor Enrique Marco Dorta, 
quien goza en mi país de una justa admiración. En esta ciudad especialmente, se le recuerda con afecto y gratitud. Su monumental obra sobre Cartagena es la más notable contribución, tanto artística como literaria, sobre lo que ella representa en la historia de la cultura y civilización españolas en el Nuevo Mundo. Sabré agradecerle me haga el favor de presentarle en mi nombre un atento saludo.

Le envío también, por esta misma vía, el libro recién editado del doctor Jorge Zalamea sobre Luis Carlos. En preparación y bastante adelantado, está próximo a salir el libro de don Ramón de Zubiría, actual Rector de la Universidad de los Andes en Bogotá, en el cual recoge la producción poética de mi hermano, con un juicio crítico sobre él. Ambos eminentes literatos ven con satisfacción que usted quiera rendir a Luis Carlos el honroso homenaje de su simpatía. Le informo, además, que, según acabo de ver en el «Boletín Cultural y Bibliográfico de la Biblioteca Luis Angel Arango», del Banco de la República, volumen V, número 9, 1962, página 1235, se ha editado en Moscú, edición del Estado, un tomo de versos de mi hermano, traducidos al ruso por O. Savich.

Continuaré enviándole otros datos y documentos, y cuente usted con la colaboración que pueda prestarle con el mayor gusto. Será para mí un honor y me dará un verdadero placer continuar con usted estas relaciones de amistad que se han iniciado en tan gratas circunstancias para mí.

Le reitero mi personal reconocimiento y quedo a sus muy estimables órdenes, como su atento servidor y amigo,

[Firma]

Domingo López Escauriaza

\section{LUIS C. López (DATOS BIOGRÁFICOS)}

Luis Carlos nació (11 de junio de 1879) en el hogar formado por Bernardo López Bessada y por Concepción Escauriaza de López. Tanto aquél como ésta tuvieron ascendientes españoles. La madre, especialmente, era hija de Benito Escauriaza, vasco. Una anécdota de familia que ilustra el linaje del poeta. La abuela materna de Luis Carlos preguntó una vez a su esposo, señor Escauriaza, qué familia cartagenera tenía alguna semejanza con la de él en España. Y su respuesta fue: la de don Domingo López de Osse y su señora Concepción Bessada de López. Precisamente quienes irían a ser - muchos años después- los abuelos del poeta. 
La infancia de Luis Carlos transcurrió sin ninguna característica especial. Fue el primogénito de una familia de once hermanos: cuatro mujeres y siete hombres. Las primeras fallecieron prematuramente en los primeros años de su existencia.

Cursó estudios secundarios en dos planteles de gran reputación docente en Cartagena: allí hizo sus estudios de bachillerato hasta terminarlos normalmente. Aspiró a hacer carrera médica y llegó a ingresar a la respectiva Facultad. Pero la guerra civil de 1899, que asoló al país durante tres años, tronchó estas aspiraciones.

Puede decirse que Luis Carlos, desde temprana edad, tuvo una franca e irresistible vocación a las letras. Además, desde el colegio se aficionó al dibujo, por el cual demostró notables aptitudes. Sin embargo, fuera de escarceos en la caricatura, no hizo obra alguna de aliento pictórico. En sus sonetos se nota muy claramente esta tendencia a pintar con inconfundibles colores el paisaje en que se mueven los tipos de su tierra nativa y en general todo el trasfondo de su poesía humorística.

Temperamentalmente, Luis Carlos fue la negación de todo gregarismo. Tímido pero no reconcentrado, huyó de las reuniones sociales, por las que tuvo siempre cierta despreocupación. En su juventud, sin embargo, le gustó el baile y frecuentó las fiestas de sociedad. Muy joven - a los veintiséis años- casó con doña Aura Cowan Tono, dama perteneciente a una rancia y distinguida familia cartagenera. En su matrimonio tuvo tres hijos: Marina, Bruno y Carlos. Tanro la viuda como los hijos viven actualmente en Cartagena.

En la época en que transcurre la vida del poeta en esta ciudad de su nacimiento, el ambiente literario era propicio a la exaltación lírica del romanticismo y ya, además, habían hecho su aparición Rubén Darío, Lugones y Amado Nervo. En Colombia el maestro Guillermo Valencia, con su obra de versos Ritos, orientaba las corrientes del modernismo. Luis Carlos inicia su vida literaria con la publicación en España de su librito de versos De mi villorio, que le vale una carta consagratoria de don Miguel de Unamuno. Anteriormente, en revistas y periódicos, había publicado algunas de sus producciones. Como dato biográfico, siendo estudiante sostuvo, en colaboración con uno de sus condiscípulos, un pequeño periódico que llevó por título Rojo y Negro. Luego vendrían las otras obras: Posturas dificiles, Por el atajo y Varios a varios. 
No se cuidó Luis Carlos de la publicidad ni del réclame. Al contrario. A este respecto puede decirse que para él su fecunda labor literaria no tuvo jamás la menor importancia. Vivió, puede decirse, aliterariamente. Sin que ello implique desdén por el culto de lo que fue su absorbente tarea: la creación estética.

Tuvo Luis Carlos grande admiración por los más altos valores intelectuales de la generación del 98 en España. Con todos ellos mantuvo relaciones intelectuales y recibió las mejores pruebas de amistad y compañerismo. Su biblioteca, que enriqueció constantemente, pues era un lector infatigable, no fue la colección de obras sin método ni clasificación. En ella, más que en ninguna otra parte, dejó la profunda huella de su vocación literaria y de sus gustos y predilecciones. Los escritores y poetas de aquella generación que marcó una época gloriosa en las letras peninsulares tuvieron para con Luis Carlos muy deferentes demostraciones de aprecio y simpatía. Entre ellos, Unamuno, Valle Inclán, Baroja, etc.

Un dato que generalmente ha escapado a los biógrafos de Luis Carlos. Por los años de 1916 a 1917 apareció en Cartagena un diario que, dirigido por el poeta y por su hermano José Guillermo López, causó cierta extrañeza en la opinión pública. El nombre de aquella gaceta era el siguiente: La Unión Comercial. Paradójicamente, el poeta hacía irrupción en el campo de los negocios. Pero no había motivo para tanto aspaviento. En Colombia - país de poetas hasta principios de este siglo- también los políticos y estadistas editaban sus órganos periodísticos con títulos similares que nada tenían que ver, esencialmente, con el doctrinarismo que informaba sus campañas y tendencias. Tal fue el caso de la Gaceta Mercantil de quien sería luego presidente de Colombia, años después: el doctor Manuel Murillo Toro.

Una característica de este diario, que se editaba bajo la dirección de Luis Carlos y de José Guillermo, su hermano: tenía una página en inglés. Fue el primero y quizá el único periódico bilingüe que haya tenido el país. En él, como era apenas lógico, aparecían producciones poéticas de distintos autores colombianos y extranjeros, bajo la rigurosa selección de Luis Carlos. Pero otra característica que habla del temperamento apolítico del poeta: siendo éste de convicciones liberales y democráticas, no fue político militante ni aspiró a cargos de representación en el Estado. No fue gobernador, ni ministro del despacho ejecutivo, ni embajador. 
Por dos ocasiones desempeñó cargos consulares: el primero en Munich (Alemania) y el segundo en Baltimore (Estados Unidos). Pero sin que el ejercicio de ellos lo consagrara como funcionario de carrera. En su obra poética se nota la influencia, aparentemente epidérmica, de sus viajes al exterior.

Algo también muy original y paradójico: Luis Carlos —que no tenía nada de pragmático- ejerció el comercio, más que por vocación o por necesidad, por complacer a su padre, que así quiso asociarlo a sus empresas mercantiles. Había que ver al poeta en el almacén de abarrotes y de artículos muy finos donde él recibía a sus amigos y compañeros de arte. Era el rendez-vopus de escritores y artistas. Irónico y burlón, el poeta atendía más que a la clientela burguesa a los bohemios y trashumantes que tenían algo que contar o que recitar por encima de las cosas materiales. Quizá a ello se deba la rebeldía del poeta ante la rutina del ambiente y la mediocridad circundante de la gente, que no comprendía ni podía admitir que el Parnaso tuviera algo que ver con Mercurio. De ahí el rictus amargo, en apariencia, del poeta, que se burlaba quevedescamente de sus paisanos, en sonetos que eran, en el fondo, saeta e invectiva contra el destino.

Pero no había en el espíritu del poeta nada acibarado ni la huella de una amargura. Fue, por el contrario, ingenuo y casi infantil en sus sentimientos íntimos. Afectivo en el ámbito familiar, hogareño, misántropo en su actitud de defensa ante las intrusiones de la chabacanería y de la estulticia, daba rienda suelta a su ternura y a sus afectos más entrañables hacia los seres que formaron el objeto de sus preferencias. Este distanciamiento no era en él postura aristocrática ni presunción de casta. Sencillamente fue en sus gustos y en sus costumbres un hombre sin complicaciones. Intelectualmente aparecía como un enfant terrible.

$$
* * *
$$

Al llegar a esta parte de un bosquejo biográfico de Luis Carlos, conviene recordar esta anécdota: don Antonio Balbuena, un crítico español, misántropo (éste sí) y fanático en gramatiquerías, en uno de sus terribles comentarios se refirió al poeta cartagenero en una forma que le era familiar: le negó todo y lo puso de oro y azul. Luis Carlos se encogió de hombros ante el ogro y lo castigó con una de sus sonrisas irónicas... 
Otra vez tuvo algo que ver con el autor de Prosas profanas. En el sonado incidente literario Rubén Darío le reconoció y elogió la capacidad y el mérito de la obra poética de Luis Carlos.

Para quienes quieran ahondar en su compleja personalidad literaria, bastaría este dato: Luis Carlos no fue un intrépido luchador ante la vida. Indiferente a la conquista del dinero, fue extraño a todas las manifestaciones del mundo burgués. Para él fue siempre un exacto síntoma de la sociedad en que vivía, la tendencia hacia el filisteísmo. En ese aspecto, pese a sus aparentes actividades mercantiles, él encarnaba todo lo contrario. Lo cual explica, psicológica y moralmente, la posición intelectual del poeta.

$$
* * *
$$

Casi toda la vida del poeta transcurre en una ciudad quieta, casi monacal, de fines del siglo XIX. Su juventud y parte de su madurez están influidas por este ambiente provinciano. Cartagena - su tierra natal- es una visión retrospectiva de la España conquistadora y de la época de los bucaneros. La espada y la cruz, la mitra y la toga, la Inquisición y los oidores, todo el aparato militar y caballeresco, es el pasado que se inmoviliza pétreamente en los viejos torreones y en las garitas, en los conventos y en los castillos medievales. E1 poeta canta a su ciudad y añora las botijuelas, el candil y las águilas caudales cuando los hijos de Cartagena no eran «una caterva de vencejos».

En Cartagena se ha erigido un monumento en honor del poeta. En él se simbolizan "los zapatos viejos», que en la imagen poética del humorista cifra él el cariño que le tiene a su ciudad nativa. Es éste un homenaje un tanto estrafalario: pero en verdad nada personifica tanto el genio literario del poeta cartagenero como esta simbiosis entre su vieja urbe y sus zapatos viejos. Rancia y desaliñada, la ciudad cantada por José María de Heredia adquiere resonancias líricas en el autor de «Posturas difíciles».

$* * *$

En vida se le rindió un homenaje nacional. Guasonamente el poeta no se quiso dejar «coronar» y en un soneto que escribió con este motivo reflejó sus sentimientos íntimos ante aquella manifestación de sus admiradores.

$$
* *
$$

En otra ocasión, se celebraba un concurso poético y se distribuían los premios a los vencedores, en unos «Juegos Florales». Luis Carlos se pre- 
senta al concurso; pero lo hace a través de un «Fígaro» -aficionado a la poesía - quien bajo un seudónimo envía el soneto que luego iba a ser galardonado con el primer premio. $\mathrm{Y}$ cuando se presenta el testaferro literario, en el proscenio del teatro, en la velada lírica, el público oye leer el soneto y un solo aplauso envuelve el nombre de Luis Carlos, a quienes todos reconocen como el autor de la broma. Este soneto es el siguiente.

\author{
ANTOLOGIA A SU MAGESTAD \\ DOÑA MARIA DE LEON Y DEL CASTILLO, \\ REINA DE LOS ESTUDIANTES
}

Sepa S. M. Doña María

de León y del Castillo, que deseo tañer -melificando mi alegríala guzla estudiantil en su torneo!...

Oh! si pudiera audaz en mi osadía llevar como un olímpico trofeo - para divinizaros, Reina míala melodiosa cítara de Orfeo!

O tornar a los tiempos de la incauta vida del sacro Pan, el de la flauta pastoril de los siete áticos trinos,

para cantaros, Soberana y Diosa, mientras las ninfas, en la paz umbrosa, trenzan risueños bailes campesinos!...

\title{
Antonio S. Guerra \\ (Libanés) \\ Juan Cualquiera.
}

La cultura intelectual de Luis Carlos fue, en un medio como el de Cartagena, la obra de un autodidacta. Leía mucho; era un devorador de libros; no tuvo, sin embargo, una disciplina especial. Sus preferencias: la novela, las descripciones de viajes, desde luego los versos, y sus lecturas iban más allá: a veces, también, obras filosóficas, ensayos. Además, se mantuvo siempre al día con una curiosidad insaciable por conocer el movimiento literario de Europa y de los Estados Unidos. Así como el de la América indo-española. Conoció y trató personalmente a grandes figuras. de la intelectualidad hispanoamericana. Una manera de ser de él, inva-- 
riable hasta sus últimos momento, fue la de no querer presentarse en público a declamar sus versos. Le hicieron innumerables invitaciones, tanto en Colombia como en el exterior, para que diera recitales y conferencias. Siempre se excusó. En los Estados Unidos varias Universidades, en distintas ocasiones, le solicitaron su colaboración y le ofrecieron estímulos económicos para que les enviara sus producciones poéticas todavía inéditas. Fue en su actitud de aislamiento un irreductible.

Visitó la capital de su país el año 1906, cuando se viajaba hasta Bogotá usando los medios de locomoción más primitivos. Fue entonces -ironía de su destino- en cumplimiento de una misión comercial. En la «Atenas suramericana», como graciosamente se le llamaba a aquella ciudad, tuvo ocasión de relacionarse con los literatos de ese tiempo. Ya él había editado en Madrid su primer libro de versos, De mi villorio. El encuentro de Luis Carlos con los poetas de su generación fue motivo para él de muchos homenajes. Ese fue su primer y único viaje a la capital de la República. De otras partes del país - de Medellín principalmente- recibió obligantes invitaciones para que fuera a dar conferencias y recitales. No quiso hacerlo sistemáticamente.

$$
* * *
$$

Antes de su viaje como cónsul a Alemania ya había visitado Nueva York. En Munich permaneció algún tiempo. Para él su contacto con la vieja civilización de Europa fue de grande interés espiritual. Satisfizo así una aspiración de su vida. Pero como había de plasmar toda su personalidad con actos sucesivos que eran la contradicción de su vocación literaria, el poeta estuvo bajo el signo de Mercurio. En Baltimore permaneció casi siete (7) años: allí, entre facturas consulares y documentos de embarque, transcurrió su vida, entregado a la lectura y sin dejar de escribir sonetos. Hasta su residencia en aquel puerto norteamericano le llegaban invitaciones a colaborar en revistas importantes de los Estados Unidos. Como se ha dicho anteriormente, las declinó siempre, invariablemente.

$* * *$

Dado su temperamento poco inclinado a formar parte de asociaciones, Luis Carlos hizo una excepción al participar en las actividades de una institución que en Cartagena llevó el nombre de El Bodegón. Tal entidad 
tuvo mucho de festiva, y en sus orígenes, así como en sus funciones, los fundadores de ella quisieron darle un carácter que la alejaba de toda solemnidad académica, aun cuando predominó entre sus socios la alegre camaradería y el culto a todas las empresas idealistas. El Bodegón tuvo, en serio y en broma, un presidente vitalicio, al cual se le daba el nombre de Rey Jacob (de apellido Delvalle), un caballero muy apreciado y querido por todos sus compañeros y a quien el poeta López distinguió siempre con su afecto y simpatía. Ya se comprenderá que no se trataba de un reinado carnavalesco ni de una pantomima de circo. La institución fue creciendo y arraigando en las capas culturales de la ciudad. Y se fue proyectando en los círculos intelectuales de toda la nación. Para que se comprenda mejor, El Bodegón fue la casa de los escritores y artistas, que en ella se reunían para festejar sucesos de alguna trascendencia, para rendir el homenaje consagratorio a sus nuevos socios y también a los huéspedes ilustres de la ciudad. Y había que ver lo que significaba en regocijo y en folclórico entusiasmo cada vez que el Rey Jacob y su estado mayor cumplían el ritual de clásica vigencia en sus memorables sesiones. Pero no podía falta, entre literatos, el órgano de difusión publicitaria, y lo tuvo con periódica circulación, bajo el nombre de la celebérrima casa. Fue en verdad una revista ágil, pintoresca, sesuda en ocasiones, escrita con ingenio, desde cuyas columnas los mejores exponentes de la intelectualidad cartagenera y aun del resto del país colaboraron en prosa y en verso. Entre ellos, Luis Carlos, víctima en ocasiones de más de una trastada literaria que él festejada alegremente.

$$
* * *
$$

E1 medio familiar fue para Luis Carlos su refugio. Se ha hecho de su vida por quienes en realidad no lo conocieron en la intimidad una deformación de lo que ella fue. Consagrado a los suyos, expansivo y cordial, era un buen miembro de familia. Adoró a sus padres, especialmente a su madre, que sobrevivió a su esposo en más de veinticinco años, y ya nonagenaria acompañó a sus hijos. Porque una característica de esta vida íntima de Luis Carlos: él formó con sus hermanos una sola unidad de familia. Se le creyó entregado a la bohemia y se le presentó falsamente como asiduo concurrente a bares y cantinas. Nada más ajeno a la realidad. Luis Carlos tuvo ciertamente aficiones a pasar con amigos ratos «alegres como un vaso de vino moscatel». Pero dentro de los límites del decoro y de la pulcritud moral. En esto fue, como en tantas otras cosas, un hombre de su tiempo y de su generación. No fue trasnochador: casi pudiera decirse que 
vivió con los hábitos de un burgués. En la intimidad era sencillo, afectuoso, con sus dejos de ironista, que fue su característica invariable.

Otro dato biográfico casi incidental en la vida de Luis Carlos. En la historia de Colombia ocurría generalmente que a la primera magistratura del país llegaban, con la gramática en la mano, humanistas, filólogos y escritores que habían hecho carrera en las letras. Esta tradición no se ha interrumpido del todo. Pues bien: en 1910 estaba de presidente de la República el doctor Carlos E. Restrepo, periodista y poeta. Entonces había triunfado en las elecciones el movimiento llamado «la unión republicana», del cual era su jefe principal de más prestigio el doctor Restrepo. Y Luis Carlos, por una de esas ironías que tanto le seducían a su espíritu, recibió la consagración de ser candidato a la Cámara de Diputados de su país. ¡Cuán ajeno era él a estas maniobras caciquiles! Naturalmente, el voto comicial le fue totalmente adverso. La bazofia de los políticos de tres al cuarto recibió la dura paliza de uno de sus más cáusticos sonetos.

Sus versos expresan mejor que todos los datos biográficos cuáles fueron sus sentimientos íntimos y su actitud ante la vida.

$* * *$

Hasta aquí se ha procurado resumir lo que fue Luis Carlos en sus aspectos más salientes. Falta, sin embargo, conocer si, como aparece en algunos de sus sonetos, fue un agnóstico en religión y un furibundo anticlerical. Rio mucho, volterianamente, sobre todas las cosas divinas y humanas. Pero no hizo de su rebeldía meramente intelectual ninguna profesión anticatólica. Y le tocó con el más soberano respeto, como compañera de su vida, a la dama a quien llevó al altar: una mujer de profunda devoción religiosa, educada con severo esmero dentro de un ambiente casi monástico. Detalle también de su vida: en su hogar reinó siempre la más perfecta armonía y una diáfana felicidad. Porque en Luis Carlos su escepticismo y sus irreverencias («qué hago con este fusil?» en el soneto sobre el cura de pueblo) no traspasaron las fronteras del libre pensamiento y de la tolerancia ante las ideas ajenas. No hizo tampoco una postura de su despreocupación religiosa. Era, además, tan demasiado humano que, al morir, conversó con el sacerdote que le visitó y le brindó los auxilios espi- 
rituales. Su corazón no podía negar a la madre de sus hijos —una santa mujer- esta última satisfacción.

Estas líneas, escritas al calor de los recuerdos familiares, tienen un defecto: las dicta el sentimiento de quien estuvo muy cerca de Luis Carlos y recibió, como su hermano menor (el penúltimo), las más efusivas manifestaciones de su afecto entrañable. Puede, por lo mismo, que no sea rigurosamente imparcial, aunque sí absolutamente verídico, en sus apreciaciones sobre el hombre y el poeta en su intimidad. Su obra literaria queda al juicio de los críticos.

Cartagena, Colombia, marzo de 1963. 